\title{
Australia's Out-Dated Concern over Fishing Threatens Wise Marine Conservation and Ecologically Sustainable Seafood Supply
}

\author{
Robert Kearney \\ University of Canberra ACT, Cronulla, Australia \\ Email: bob.kearney@canberra.edu.au
}

Received February 14, 2013; revised March 19, 2013; accepted March 30, 2013

Copyright (C) 2013 Robert Kearney. This is an open access article distributed under the Creative Commons Attribution License, which permits unrestricted use, distribution, and reproduction in any medium, provided the original work is properly cited.

\begin{abstract}
Seafood plays an important role in human nutrition and its increased consumption is actively recommended for sustenance and health benefits in both developing and developed countries. In parallel to this, the public receives confusing advice as to what seafood is sustainably produced and is frequently misled about the environmental impacts of fishing, especially in locations such as Australia where contemporary fishery management has a conservation and sustainability focus. It is recognised globally that Australia's traditional fishery management driven by strict sustainability and biodiversity regulations, has achieved impressive results in managing both fish stocks and the effects of fishing on marine environments. Despite this, continued pressure from non-government organisations (NGOs) and a perpetuation of the misuse of management terms such as "overfished" is used to promote the misguided need for ever increasing fishing restrictions, most obviously in "protected areas". This paper questions the motives of some NGOs and governments in Australia in pursuing additional restrictions on fishing which are mostly unnecessary and disproportionate to the sustainability requirements of other sources of food. This is done within the context of the global need for sustainable seafood supply and the need for effective marine conservation that addresses all threats to marine ecosystems in proportion to the magnitude of each threat.
\end{abstract}

Keywords: Seafood Sustainability; Marine Conservation; Misguided Fishing Restrictions; Inefficient Conservation; Distorted Public Perceptions

\section{Some Contradictions}

Australians are being told by responsible health practitioners and related Government agencies that it is necessary for their physical and mental health to eat more seafood [1]. Coupled with seafood's unequalled health benefits is its place as a preference on the menus of Australia's most acclaimed restaurants and as the number one life-style, or at least special-occasion, choice of food for many Australians. Australians also like to buy Australian and eat fresh, local seafood, including regional specialities, for example Western Australian lobsters, Queensland scallops or Coffs Harbour prawns. Being able to eat fresh local seafood provides more than a culinary delight; it underpins established cultural and heritage traditions, not only for indigenous Australians, particularly in coastal regions. Ironically, the public's enthusiasm for eating fish is simultaneously being dampened by warnings that they should only do so with caution because it is claimed that fishing is a major factor in the degradation of the world's oceans. These warnings, seeded predominantly from those non-government organisations (NGOs) that stand to benefit from fostering gloom and doom and sensationalism [2] are not consistent with the most recent assessments of the impacts of fishing and, most importantly, they are based predominantly on information that is not relevant to contemporary Australia. Fishing has become very conservatively managed in Australia and it no longer represents the serious or irreversible threat [3] for which it continues to be accused. The major threats to Australia's living marine resources are pollution in its many forms, introduced organisms and inappropriate coastal development [3].

Despite being ranked fourth out of 52 countries surveyed for sustainable fisheries management [4], and having a huge and relatively lightly exploited exclusive economic zone (EEZ), Australia continues to import the bulk $(>70 \%)$ of seafood consumed domestically. This 
deficit in supply and demand, by volume, continues to worsen (the value of imports and exports are approximately equal but exports are dominated by much smaller quantities of expensive products including abalone, lobsters and sashimi-grade southern bluefin tuna). Australia needs more seafood and the world's population, particularly in developing countries, needs more protein and other nutrients that are concentrated in seafood [5]. Australia's imports come predominantly from Thailand (ranked $42^{\text {nd }}$ out of 52), China $\left(22^{\text {nd }}\right)$, New Zealand $\left(8^{\text {th }}\right)$ and Vietnam $\left(45^{\text {th }}\right)$, and so Australia is not only outcompeting buyers in numerous developing countries for fish that could be consumed for health and social benefit in those countries but it is also exporting responsibility for the sustainable harvest of the world's oceans to countries that are not as good at managing sustainability as is Australia [6].

Against this background Australia has recently announced [7] the intention to close huge areas of ocean to fishing without adequate consideration of how those areas might be used to help meet Australia's future seafood needs. These areas include approximately one million square kilometres in the Coral Sea [8], which has the potential to yield at least sufficient tuna to displace Australia’s biggest seafood import item.

\section{A Historical Perspective of Seafood Appreciation and Fisheries Management}

Seafood has been a key ingredient of human diets in most regions since hunting and gathering evolved to include aquatic organisms. The consumption of fish is considered to have been critical for the development of the superior intellectual capacity of the human brain and the emergence of Homo sapiens from areas around Africa where fish was readily available [9]. For millennia fish has been appreciated as a highly desirable form of food. As time progressed its desirability continued to increase, as has the scientific evidence of its health benefits.

In spite of the importance of seafood as a source of sustenance, the management, or even monitoring, of fishing, remained rudimentary in most countries until the middle of the 20th century and even into the 1990s. Most managers continued to be comforted by the belief that the oceans were limitless and marine fish were immune from human attempts to overexploit them, as had been documented in Mare Liberum (The Free Sea) in the early 17th century [10]. A combination of ignorance, inertia, inability, short-term self-interest and reluctance to effectively address even obvious problems became institutionalised. Reluctance to take action remains in many countries, particularly in the developing world where the pressure to allow individuals to continue to exploit even over-exploited resources as the last common-property source of food for the socially disadvantaged, is extremely difficult to counter. Even developed countries are not immune from avoidance of the obviously necessary management measures. This is a particular problem when countries share resources, as most do, and international cooperation is necessary, but elusive. The European Union provides high-profile examples of continuing ineffective fisheries management for this reason.

By the beginning of the 21st century, however, many countries had begun to correct previous excesses or failures. In countries with stable governance and effective single nation authority for oceanic resources, such as Australia and New Zealand, overfishing was surprisingly quickly reined in. As discussed below, in Australia's Commonwealth managed fisheries overfishing was reduced from approximately $40 \%$ to little more than $10 \%$ of assessed stocks in less than a decade, 2004 to 2010 [11], even under the excessively conservative terminology and assessment processes used to define "overfishing”. Despite these impressive improvements in fisheries outcomes sections of the NGO industry have not diminished their anti-fishing rhetoric, even as fisheries management has improved and much greater threats to marine resources, such as pollution and introduced organisms, have been described [12]; sensationalised projection of gloom and doom remains a primary driver of the anti-fishing component of the NGO industry [2].

\section{The Effectiveness of Australia's Fisheries Management}

Australia has not always had adequate fisheries management. There were extremely few limits on effort or catch in Commonwealth and most east coast fisheries in Australia prior to the 1980s. As a result over-capitalisation of fisheries and "overfishing" became common; as recently as 2004 more than $40 \%$ of Australia's Commonwealth managed fish stocks for which there were sufficient data to complete an assessment were assessed as still subject to overfishing [11], but by this time attitudes had changed and management had begun to respond. By 2006 overfishing had been eliminated in all but $11 \%$ of assessed stocks. In response the percentage of stocks assessed to not be in an overfished state increased from $60 \%$ in 2004 to $84 \%$ by 2010 [11]. This rapid recovery highlights the resilience of fish stocks and their supporting environments to extraction by fishing. It confirms that the impacts of even inadequately managed fishing in Australia were not irreversible. It also demonstrates the effectiveness of traditional fisheries management techniques (effort and catch controls) to protect and even restore fisheries resources.

Australia's impressive record in managing fisheries to ensure the sustainability of underlying resources has been internationally acknowledged. As noted above, in 2009 Australia was ranked $4^{\text {th }}$ out of 52 countries surveyed for 
sustainable fisheries management [4]. But Australia has the world's third largest marine EEZ and yet is ranked only $61^{\text {st }}$ out of 235 countries and territories whose total fisheries production was estimated [13]. While Australia's waters are not amongst the world's most productive, the combination of area and productivity indicates that Australia's total fisheries resources are lightly exploited. It also confirms that full development of fisheries potential is not a current priority for Australian governments.

In reality Australia's fisheries management has not been balanced. It historically permitted overcapitalizetion of many fisheries and it has more recently failed to encourage development of new sustainable fisheries, as required under its national strategy of Ecologically Sustainable Development (ESD). In spite of the limited economic efficiency in Australia's fishing, fisheries management in Australia has, as discussed above, been demonstrably effective for conserving and restoring fish stocks. Adherence to the simple principle of reducing fishing effort and/or catch when the relevant assessment indicates such a necessity is not difficult; effective control of fishing for conservation purposes by traditional fisheries management techniques is technically relatively easy in countries with sound governance and control of the resources that surround them.

\section{Imbalance in the Intent and Use of the Existing Legislation}

All state and Commonwealth legislation in Australia must be consistent with the principles of ESD [14] which require that all fisheries must be sustainable and not likely to cause irreversible damage to other species, habitats or their underlying ecosystems. Fisheries management legislation within Australia therefore requires conservation objectives to receive priority over objectives related to exploitation. This is exemplified in the various state fisheries management acts; for example the New South Wales (NSW) Act lists the fisheries management priorities: "In particular, the objects of this Act include: 1) to conserve fish stocks and key fish habitats; 2) to conserve threatened species, populations and ecological communities of fish and marine vegetation; 3) to promote ecologically sustainable development, including the conservation of biological diversity, and, consistently with those objects; 4) to promote viable commercial fishing and aquaculture industries; and 5) to promote quality recreational fishing opportunities..." [15].

The Commonwealth Fisheries Management Act gives greater priority to controlled exploitation by listing objectives as follows: “1) implementing efficient and costeffective fisheries management on behalf of the Commonwealth; and 2) ensuring that the exploitation of fisheries resources and the carrying on of any related activeties are conducted in a manner consistent with the princi- ples of ecologically sustainable development and the exercise of the precautionary principle, in particular the need to have regard to the impact of fishing activities on non-target species and the long term sustainability of the marine environment..." [16]. Commonwealth regulation of the environmental impacts of fishing are however, further emphasised in the Environmental Protection and Biodiversity Conservation (EPBC) Act [17] which overrides the Fisheries Management Act. All Commonwealth fisheries and all export based, state-managed fisheries have been required to be assessed under this Act since 2002. The collective legislative requirements for the conservation of fish and their habitats in Australia are compelling.

In contrast the legislative requirements for the prevention of damage to fish stocks, habitats and biological diversity from non-fishing impacts, such as pollution, inappropriate development and introduced organisms are far less prescriptive and do not all have the same degree of Commonwealth oversight. For example, the Commonwealth policy on pollution defers to the states as follows: "Pollution control is the responsibility of state and territory environment agencies" [18]. In addition, the effectiveness of controls on other threats to marine environments is not subject to the same degree of annual assessment and public scrutiny as are the controls on fishing. Unfortunately, and disappointingly, control of these real and significant threats is not subject to rigorous NGO activism.

From the perspective of the seafood-consumer, there is a complete lack of legislation, or even relevant policies, that mandate effort to secure the sustainable supply of seafood to address Australia's future seafood security. This is a stark indicator of the imbalance in legislated requirements for the conservation and the sustainable use of marine resources as anticipated under Australia's guiding principle for natural resource conservation and management, ESD. The Commonwealth Government's recent food security Green Paper acknowledges that seafood is the one major food type for which Australia has completely inadequate domestic supply [19, p. 16], but then effectively ignores the predicament in the remainder of the paper [19]. Prominent NGO campaigns promoting even more restrictions on fishing dismiss the problem of future seafood supply, usually by either ignoring it or stating that because we have imported seafood for years "we just need to import more" [20]. Paradoxically, most of these campaigns rely heavily on the claim that globally "The decline in abundance of fish and other creatures is accelerating” [21] and give prominence to sensationalised assertions, for example that by Worm et al. [22] that this decline in world fisheries is so great the world will have run out of seafood by 2048. The espoused strategy of an increased Australian reliance on imports to 
support closure of more areas to domestic fishing is not only inconsistent with current information on the sustainability of Australia's fisheries, it is actually illogical. It is also inconsiderate of the needs of other countries. Furthermore, considering the increasing size and affluence of the middle classes in the countries from which Australia currently imports its fish it must be anticipated that competing for seafood from these, and even other countries, will become increasingly difficult and costly.

\section{Sustainable Fishing; The Problem with Terminology}

The distinction between well-managed fishing and destructive fishing practices, including continued excessive overfishing, is critical. The failure, commonly deliberate by the lobby for greater restriction on fishing, to differentiate between the impacts of well-managed fishing and those when and where fisheries management is absent or inadequate is at the core of current public misunderstanding. The incorrect attribution of the problems of overfishing, to fishing in general, is shamefully exploited by the anti-fishing lobby. It is even misused by the Australian Government, for example in its recent Regulatory Impact Statement (RIS) on the national system of marine reserves [23].

In countries, such as Australia, with well-managed fisheries, the destructive fishing practices that have been responsible for the overt damage to habitats, often depicted from other countries to engender support for anti-fishing campaigns, are illegal and have been largely eliminated. In the few areas where damaging practices, such as bottom-trawling in areas with vulnerable benthic structure, are allowed because of their relative efficiency in accumulating catches, they are constrained within the limits of total resource and environmental sustainability. This is normally done by restricting the activity to within only a fraction of the total area of the species and habitats in question, for example the fishery for orange roughy in Australia which did locally over-exploit resources and damage benthic structures, particularly on several seamounts, is now allowed in only 3\% of the area of distribution of this previously overfished, but currently under-utilised species [24].

In countries such as Australia which have strong fisheries legislation, overfishing to the degree that it threatens the survival of target species or associated ecosystems, is illegal. If serious overfishing is detected to have occurred recovery plans are mandatory and have been proven successful. Furthermore, as undesirable as overfishing is it should not be over-dramatized; stocks that are moderately overfished or subject to limited overfishing are still biologically sustainable. In Australia, they have been demonstrated to recover when traditional fish- eries management is diligently applied. No species has ever been documented to have been fished to extinction in Australia even though there was considerable and sustained overfishing in numerous fisheries up to the time of the marked improvement in fisheries management around the turn of this century. In countries or areas where fisheries are well managed the expression "overfished" should be regarded as the need for caution or possible restraint, not a pronouncement of an environmental catastrophe that has already occurred.

\section{The Environmental Credentials of Well-Managed Fishing as a Source of Food}

Comparison of fishing with Australia's other sources of food is illuminating, even though great caution must be exercised when comparing what management is appropriate in terrestrial and marine environments [3]. Most intensive agriculture, such as vegetable growing, begins by clearing native vegetation, tilling the soil, introducing and cultivating foreign species, adding fertilizers and usually pesticides and making sure no native species disturbs the crop by making a comeback. Yet agriculture is accepted by civil societies to be essential. Consumption of vegetables, (in particular "organic" ones which tend to require greater land area for production), which in Australia are virtually all introduced species, is promoted as an environmentally responsible mode of sustenance! Australia's capture fisheries are not based on introducing foreign species or deliberately eliminating native ones, even in parts of areas, and they do not directly use fertilizers, insecticides or herbicides, all of which when used in agriculture have local impacts and often down-stream negative effects on ecosystems, particularly aquatic ones, and the varied resources they support.

Australia's numerous fisheries and environmental management acts demand that fishing must not seriously and irreversibly damage habitats (detailed above); compared to other forms of food production, fishing is required to be extremely environmentally benign. The fundamental objectives of state fisheries management are clearly stated in the relevant acts to be the sustainability of native, natural resources and the habitats that support them; they must not be irreversibly damaged. Very little, if any, intensive agriculture could meet the rigorous environmental standards of Australia's fisheries legislation.

A fishery that takes only the surplus production, as by definition, a well-managed fishery must, and where incidental impacts on habitats and other species are sustainably managed, as they are required to be under Australian Commonwealth and state legislation, represents the ultimate organic, environmentally benign and sustainable source of truly free-range, endemic, Australian food. 


\section{Why Does Australia Allow Some NGOs and Self-Interest Groups to Control the Seafood Supply Agenda}

Australian governments and the seafood industry continue to allow public perception of the sustainability of Australian seafood to be dictated by campaigns that incorrectly imply there is considerable conservation, and even fishery, benefit in further constraining fishing. These include those by governments that claim "green" credentials by appearing to be environmentally conservative and those by numerous NGOs supporting "third party accreditation schemes" and "seafood consumer guides". Well-managed fishing, unlike urban and industrial development and many forms of agriculture, does not obviously and irreversibly change ecosystems. And noting that 54 terrestrial animals, birds and amphibians and 48 species of terrestrial plants have been driven to extinction in Australia while not a single marine species has met the same fate [25] it is difficult to understand why fishing has been singled out as requiring certification as sustainable. Why not for example sugar or beef or even lettuce?

Australia has allowed, even encouraged, the development of a sector of the NGO industry that thrives on public misconception about the sustainability of Australian seafood by advising people that many species of seafood should not be eaten and that, contrary to government assessments, only a small number are truly sustainable. There are no minimum qualifications or adequate regulatory standards required of people who publicise such "independent" assessments. The resulting practice of inadequately regulated "assessment" and even misrepresentation of the sustainability of seafood products for financial gain appears to contravene Australia's principles of fair-trade.

Third party accreditation is actually embraced by some sections of the fishing and seafood industries; it can deliver a market advantage if it is accompanied by effective advertising. It does deliver extra costs and these must be borne by consumers. Unfortunately, the broader impact of claiming only a few species are sustainable gives the public the impression that only the few fisheries able to afford third party certification are adequately managed. In effect, the market advantage it creates for a few fisheries is at the cost of a market disadvantage for the great majority of Australia's fisheries that have been assessed by governments to be sustainable but choose not to, or cannot afford to embrace, third party accreditation. Why should they have to when Australia is a world leader in fisheries management and all major fisheries are subject to regular assessment at both the state and Commonwealth level?

The outcome of current third party accreditation is that fishing in general is projected as not being a sustainable activity and therefore eating fish is not environmentally responsible. The longer-term impact is to bias public perception of the sustainability of seafood. This in turn can disadvantage all fisheries, including those which have independent certification, by leading to generic reaction against all seafood and subsequent excessive restriction of fishing.

Support for third party accreditation of seafood is not limited to some NGOs and individual fishing companies or industry sectors. Government support for third party accreditation of fishing is exemplified by the Western Australian (WA) Government allocating \$14.5 million for the "independent" pre-certification of that State's fisheries [26]. Western Australia has extremely good fisheries research and management, Government assessments in WA are based on some of the world's most reliable data and the people who do these assessments are internationally recognised; they are more highly qualified and have more relevant experience than most of those who do the bulk of Australia's "third party" assessments.

The national implications of Western Australia's actions are considerable; their international relevance is at least provocative. Western Australia has a small number of fisheries compared to other individual Australian states so the initial costs of independent assessment of all of Australia's fisheries, if done individually, will be many times the $\$ 14.5$ million being paid for pre-assessment of the 46 fisheries in WA. It will likely run into the hundreds of millions of dollars. Accreditation is an ongoing process with most schemes requiring re-assessment, usually on a three year cycle. The financial rewards for the NGO campaign and for individuals that project their own perceptions of the sustainability of Australia's fisheries are obvious. The considerable costs to Australian seafood consumers are also apparent. In addition, the small percentage of Australia's fisheries that receive "certification” in Western Australia will presumably achieve a market advantage over other Australian seafood by projecting that the product from the West is sustainable, and by the absence of certification, comparable products from other states are not.

\section{The Manipulation of Public Perception}

Incorrect public perception of the environmental impacts of fishing in Australia continues to be fuelled by the failure of Australian governments to publicly defend the internationally recognised and demonstrably conservative resource and environmental performance of fisheries management in Australia. In effect, the threat to fisheries resources and underlying ecosystems from fishing has already been largely removed or is being addressed by traditional fisheries management processes. Fishery and 
environmental legislation have provided effective protection against the effects of fishing but Australia's existing legislation does not provide adequate protection against the impacts from other threats, such as pollution and invasive species. For whatever reason, Australian governments appear not to want the public to know this!

The reluctance by governments to market the positive outcomes of demonstrably conservative fisheries management has biased public perception against the sustainability of fishing in Australia. Why do governments allow the misconception to thrive? The most likely explanation appears to be the electoral advantage for governments in fostering the perception that further restriction of fishing, particularly in so called "protected" areas where fishing is excluded, is providing appropriate and permanent protection of marine ecosystems, as claimed in many government press releases (e.g. [7]). Unfortunately the promotion of this ill-informed perception is at the expense of addressing the real threats to marine biodiversity and ecosystems, such as pollution, introduced organisms and inappropriate coastal development. Effectively managing the real threats would be far more costly and would likely provoke confrontation with the impressive and coordinated public-relations capabilities of the agriculture, mining, coastal development and shipping industries and the impressive social media campaigns of the NGO industry.

Meanwhile, Australia's fishing industries, both commercial and recreational, remain incapable of or disinterested in, forcing governments to publicly debate the strategic issues of fisheries management and seafood security, or even to force governments to defend the performance of their own fisheries research and management institutions. Neither industry has effective national coordination or gives adequate priority to strategic and long-term management. The recreational sector continues to distance itself from the need for seafood supply for all Australians by rigorously promoting preferential and disproportionate allocation of resources to anglers who constitute an estimated $19.5 \%$ of the population (Henry and Lyle, 2003); the annual catch taken by anglers (estimated to exceed 30,000 tonnes by 2000/2001) [27] was by that time already almost $19 \%$ of the current total Australian commercial fish catch (approximately 160,000 tonnes) [28]. The commercial fishing industry's actions remain disproportionately dominated by the short-term self-interest of individuals. This is exemplified by Industry representations to governments having been dominated by claims for compensation for individuals in the catching sector at the expense of national debate of the strategic reasons for, and consequences of, further restriction of seafood supply. While the seafood industry remains incapable of balancing public perceptions it appears that both appropriate marine conservation and the interests of seafood consumers will continue to suffer as governments take electoral advantage from nurturing misconceptions.

\section{REFERENCES}

[1] NHMRC, “Australian Dietary Guidelines Incorporating the Australian Guide to Healthy Eating: Providing the Scientific Evidence for Healthier Australian Diets,” 2011. https://www.eatforhealth.gov.au/sites/default/files/files/pu blic_consultation/n55_draft_australian_dietary_guidelines _consultation_111212.pdf

[2] R. Hilborn and B. Kearney, "Australian Seafood Consumers Misled by Prophets of Doom and Gloom,” 2012. http://www.sydneyfishmarket.com.au/LinClick.aspx?filet icket=L-DLXbsmBJA\%3d\&tabid=103

[3] R. Kearney, G. Farebrother, C. D. Buxton and P. Goodsell, "How Terrestrial Management Concepts Have Led to Unrealistic Expectations of Marine Protected Areas," Marine Policy, Vol. 38, No. 2, 2013, pp. 204-211.

[4] T. Pitcher, D. Kalikoski, G. Pramod and K. Short, "Not Honouring the Code,” Nature, Vol. 457, No. 7230, 2009, pp. 658-659. doi:10.1038/457658a

[5] FAO, "The State of World Fisheries and Aquaculture," 2009.

[6] R. Kearney and G. Farebrother, "Expand Australia’s Sustainable Fisheries,” Nature, Vol. 482, No. 7384, 2012, p. 162. doi:10.1038/482162c

[7] T. Burke, "Gillard Government Proclaims the Final Network of Commonwealth Marine Reserves,” 2012. http://www.environment.gov.au/minister/burke/2012/mr2 0121116.html

[8] SEWPAC, "New Coral Sea Commonwealth Marine Reserve,” 2012.

http://www.environment.gov.au/marinereserves/coralsea/ overview.html

[9] M. A. Crawford, C. L. Broadhurst, C. Galli, K. Ghebremeskel, H. Holmsen, L. F. Saugstad, et al., "The Role of Docosahexaenoic and Arachidonic Acids as Determinants of Evolution and Hominid Brain Development,” In: K. Tsukamoto, T. Kawamura, T. Takeuchi, T. D. Beard Jr. and M. J. Kaiser, Eds., Fisheries for Global Welfare and Environment, The 5th World Fisheries Congress, Tokyo, 2008, pp. 57-76.

[10] H. Grotius, R. Hakluyt, W. Welwod and D. Armitage, “The Free Sea,” Liberty Fund, University of Virginia, 2004. http://oll.libertyfund.org/index.php?Itemid=290\&id=732 \&option=com_content\&task=view

[11] J. Woodhams, I. Stobutzki, S. Vieira, R. Curtotti and G. A. Begg, "Fishery Status Reports 2010: Status of Fish Stocks and Fisheries Managed by the Australian Government," Australian Bureau of Agricultural and Resource Economics and Sciences, Canberra, 2011.

[12] UNESCO, "Mission Report: Great Barrier Reef Australia,” UNESCO World Heritage Committee, Saint Petersburg, 2012.

[13] FAO, "FishStatJ-Software for Fishery Statistical Time Series,” 2012. 
http://www.fao.org/fishery/statistics/software/fishstatj/en

[14] NSESD: AGPS, "National Strategy for Ecologically Sustainable Development,” 1992.

[15] Government of NSW, "Fisheries Management Act 1994," 1994.

[16] Commonwealth of Australia, "Fisheries Management Act 1991," 1991.

[17] Commonwealth of Australia, "Environment Protection and Biodiversity Conservation Act 1999,” 1999. http://www.austlii.edu.au/au/legis/cth/consol_act/epabca1 999588/

[18] SEWPAC, “National Pollutant Inventory,” 2012. http://www.npi.gov.au/reduce/index.html

[19] DAFF, “National Food Plan Green Paper 2012,” 2012. http://www.daff.gov.au/_data/assets/pdf_file/0009/2175 156/national-food-plan-green-paper-072012.pdf

[20] I. Zethoven, "Landline Report: Hook Line and Sinking," 2012.

http://www.abc.net.au/landline/content/2012/s3625242.ht $\mathrm{m}$

[21] I. Zethoven, "An Australian Coral Sea Heritage Park," The Pew Charitable Trusts, Philadelphia, 2008.

[22] B. Worm, E. B. Barbier, N. Beaumont, J. E. Duffy, C.
Folke, B. S. Halpern, et al., "Impacts of Biodiversity Loss on Ocean Ecosystem Services,” Science, Vol. 314, No. 5800, 2006, pp. 787-790. doi:10.1126/science.1132294

[23] SEWPAC, "Completing the Commonwealth Marine Reserves Network: Regulatory Impact Statement,” 2012. http://ris.finance.gov.au/files/2012/06/03-Completing-theCommonwealth-Marine-Reserves-Network-RIS1.pdf

[24] R. Kearney and P. J. Goodsell, "Guide to the Management and Sustainability of Seafood Supply-Orange Roughy,” Fisheries Research and Development Coporation, Canberra, 2011.

[25] SEWPAC, "EPBC Act List of Threatened Fauna,” 2009. http://www.environment.gov.au/cgi-bin/sprat/public/publi cthreatenedlist.pl

[26] N. Moore, “WA Fisheries under the Microscope,” 2012. http://www.fish.wa.gov.au/About-Us/Media-releases/Pag es/WA-fisheries-under-the-microscope.aspx

[27] G. W. Henry and J. M. Lyle, "The National Recreational and Indigenous Fishing Survey,” 2003. http://www.daff.gov.au/_data/assets/pdf_file/0011/2350 1/final_recsurvey_report.pdf

[28] M. Skirtun, P. Sahlqvist, R. Curtotti and P. Hobsbawn, “Australian Fisheries Statistics 2011,” 2012. 